\title{
HUBUNGAN KUALITAS JASA DAN HARGA DENGAN KEPUASAN KONSUMEN PANASONIC SERVICE CENTER BENGKULU
}

\author{
Andriyani Prawitasari ${ }^{1}$, Rahmad Dhoni Kaypani ${ }^{2}$ \\ ${ }^{1 \& 2}$ Universitas Dehasen Bengkulu \\ andriyaniprawitasari@gmail.com ${ }^{1}$,rahmaddhoni07@gmail.com ${ }^{2}$
}

\begin{abstract}
The objectives of this study are: (1) to determine a correlation between service quality and customer satisfaction at Panasonic Service Center Bengkulu, (2) To determine a correlation between price and customer satisfaction at Panasonic Service Center Bengkulu. The sample of this research is customers who use the services atPanasonic Service Center Bengkulu, amounting to 60 people taken by the census method. The data analysis method used is Spearman rank correlation analysis.Based on the results of the study: (1) service quality variables are significantly related to customer satisfaction at Panasonic Service Center Bengkulu, with a correlation coefficient of 0.790 and the value oft-test of 9.816> t-table 1.672. These results mean that if the quality of services is good, then customer satisfaction will increase. (2) Price variable is significantly related to customer satisfaction at Panasonic Service Center Bengkulu, with a correlation coefficient of 0.630 and the value of t-test of $6.178>\mathrm{t}$-table 1.672. These results mean that if prices are affordable then customer satisfaction will increase.
\end{abstract}

Keywords: Service Quality, Price, Customer Satisfaction.

\section{PENDAHULUAN}

Kualitas Jasa yang kurang baik maka akan memberikan efek tidak nyaman bagi konsumen yang ingin melakukan jasa servis, dan lama kelamaaan konsumen mulai beralih untuk menggunakan jasa servis di tempat lain. Dan diera saat ini terdapat banyak sekali perusahaan yang bergerak dibidang jasa servis dan menyebabkan persaingan yang sangat ketat. Dengan kondisi persaingan yang ketat itu, hal utama yang harus diprioritaskan oleh pihak Perusahaan jasa servis adalah kepuasan konsumen, agar dapat bertahan dan bersaing. Dan perusahaan servis berusaha untuk menghasilkan kinerja (performance) sebaik mungkin sehingga dapat memuaskan konsumen.

Harga merupakan hal yang paling pokok dalam perusahaan dalam mencapai keuntungan, setiap penjualan produk harus didasari dengan harga yang masuk akal,dan tidak akan merugikan kedua belah pihak baik pihak pelanggan maupun pihak perusahaan penyedia jasa atau barang. Harga adalah sejumlah uang yang dibebankan atas suatu produk atau jasa, atau jumlah dari nilai yang ditukarkan konsumen atas manfaat-manfaat karena memiliki atau mengunakan produk atau jasa tersebut. Selain kualitas jasa yang baik penentuan harga yang tepat juga akan membuat perusahaan dapat bertahan dalam jangka panjang, karena dengan harga yang sesuai dengan apa yang dipersepsikan oleh masyarakat selaku calon 
pelanggan maka masyarakat akan bersedia untuk membeli produk atau barang dan jasa tersebut. Penentuan harga yang tidak sesuai dengan ekspetasi pelanggan akan membuat pelanggan merasa kecewa dan akhirnya enggan membeli dan menggunakan produk/jasa yang ditawarkan.

Salah satu perusahaan yang bergerak dibidang pelayanan jasa servis resmi adalah Panasonic Service Center Bengkulu, adapun Panasonic Service Center Bengkulu merupakan perusahaan jasa yang melayani perbaikan alat elekronik bermerk Panasonic di kota Bengkulu. Perkembangan dan peningkatan pelayanan Panasonic Service Center bengkulu dari tahun ke tahun semakin menjadi perhatian masyarakat, Panasonic Service Center merupakan salah satu perusahaan jasa pelayanan yang mengutamakan kepuasaan konsumen sebagai indikator kualitas jasa dari perusahaan, karena sebagai perusahaan yang bergerak dibidang jasa perusahaan Panasonic Service Center tahu betul bahwa kepuasaan konsumen sebagai salah satu faktor penting dalam keberlangsungan hidup suatu perusahaan jasa. Selain dari pada kualitas jasa salah satu faktor penting dalam kepuasan konsumen adalah harga.

Sebagai perusahaan yang memiliki banyak pesaing dan untuk menarik minat konsumen agar mau menggunakan jasa servis resmi maka kualitas jasa yang baik dan penetapan harga yang tepat merupakan sebuah kunci keberhasilan Panasonic Service Center Bengkulu, mengingat masyarakat kota Bengkulu sangatlah peka terhadap kualitas suatu jasa servis dan selalu melakukan perbandingan harga sebelum menggunakan jasa servis yang dilakukan oleh Panasonic Service Center Bengkulu.

\section{TINJAUAN PUSTAKA}

\section{Kualitas Jasa}

Kualitas dapat diartikan sebagai "kondisi dinamis yang berhubungan dengan produk, jasa, sumber daya manusia, proses, dan lingkungan yang memenuhi atau melebihi harapan". Berdasarkan definisi ini, kualitas adalah hubungan antara produk dan pelayanan atau jasa yang diberikan kepada konsumen dapat memenuhi harapan dan kepuasan konsumen Tjiptono (2011:164). Konsep kualitas dianggap sebagai ukuran kesempurnaan sebuah produk atau jasa yang terdiri dari kualitas desain dan kualitas kesesuaian (conformance quality). Kualitas desain merupakan fungsi secara spesifik dari sebuah produk atau jasa, kualitas kesesuaian adalah ukuran seberapa besar tingkat kesesuaian antara sebuah produk atau jasa dengan persyaratan atau spesifikasi kualitas yang ditetapkan sebelumnya. Maka dari itu yang dimaksud kualitas adalah apabila beberapa faktor dapat memenuhi harapan konsumen seperti pernyataan tentang kualitas oleh Goetsh dan Davis dalam Tjiptono \& Chandra (2011 : 164), "Kondisi dinamis yang berhubungan dengan produk, jasa, sumber daya manusia, proses, dan lingkungan memenuhi atau melebihi harapan". Menurut beberapa definisi di atas dalam kata lain, kualitas adalah sebuah bentuk pengukuran terhadap suatu nilai layanan yang telah diterima oleh konsumen dan kondisi yang dinamis suatu produk atau jasa dalam memenuhi harapan konsumen. Tjiptono (2011:164). 
Kualitas jasa (pelayanan) memiliki beberapa dimensi atau unsur kualitas jasa (pelayanan). Unsur-unsur kualitas jasa (pelayanan) merupakan hasil temuan penelitian dari teori kualitas jasa yang disampaikan oleh A. Pasuraman. Sebagai salah satu tokoh pionir dalam pengukuran kualitas pelayanan, Pasuraman mencetuskan dimensi servqual. Dimensi ini dibuat untuk mengukur kualitas pelayanan dengan menggunakan suatu kuisioner. Teknik servqual dapat mengetahui seberapa besar jarak harapan pelanggan dengan ekspektasi pelanggan terhadap pelayanan yang diterima. (Tjiptono 2011 : 198). Kualitas jasa memiliki 5 indikator diantaranya adalah :

1. Bukti fisik (tangibles)

2. Kehandalan (reliability)

3. Daya tanggap (responsiveness)

4. Jaminan (assurance)

5. Empati (emphaty)

\section{Harga}

Setiap kegiatan pemasaran termasuk penetapan harga harus diarahkan ketercapainya suatu tujuan. Dengan kata lain, manajemen harus menentukan lebih dahulu tujuan penetapan harga itu sendiri. Menurut Kotler(2010:473), perusahaan dapat mengejar salah satu dari lima tujuan utama melalui penetapan harga, yaitu :

1. Survival (Bertahan Hidup)

2. Maximum Current Profit (Laba Maksimum Sekarang)

3. Maximum Market Share (Pangsa Pasar Maksimum)

4. Product-Quality Leadership (Kepemimpinan Mutu-Produk)

Menurut Tjiptono (2014:219) ada beberapa indikator harga berdasarkan nilai yaitu:
a. Discounting (potongan harga)
b. Odd pricing (harga ganjil)
c. Synchro-pricing ( harga singkronisasi)
d. Place differentials
e. Time differentials
f. Quantity differentials
g. Differentials as incentives
h. Penetratin pricing

\section{Kepuasan konsumen}

Menurut Lovelock dan Wirtz (2011:74) kepuasaan adalah suatu sikap yang diputuskan berdasarkan pengalaman yang didapatkan. Kepuasaan merupakan penilaian mengenai ciri atau keistimewaan produk atau jasa,atau produk itu sendiri, yang menyediakan tingkat kesenangan konsumen berkaitan dengan pemenuhan kebutuhan konsumsi konsumen. Kepuasaan konsumen dapat diciptakan melalui kualitas, pelayanan, dan nilai. Kunci untuk menghasilkan kesetiaan pelanggan adalah memberikan nilai pelanggan yang tinggi. Karena pelanggan merupakan faktor utama yang oleh perusahaan dalam menyusun rencana kebijakan bagian pemasaran yang akan dilakukan oleh pihak perusahaan. 
Adapun menurut Hawkins dan Lonney dikutip dalam Tjiptono (2014:101) bahwa indikator kepuasan konsumen terdiri dari:

1. Kesesuaian harapan

2. Minat berkunjung kembali

3. Kesediaan merekomendasikan

\section{Kerangka Analisis}

Gambar 1 : Kerangka Analisis

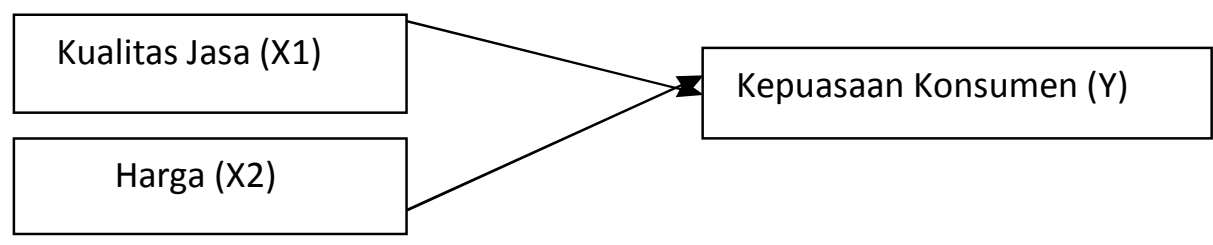

Gambar 1 diatas menunjukkan bahwa kualitas jasa dan harga mempunyai hubungan dengan kepuasaan konsumen pada Panasonic Service Center Bengkulu. Kualitas jasa (X1) dan Harga (X2) merupakan variabel bebas sedangkan Kepuasaan Konsumen (Y) merupakan variabel terikat. Dimana kualitas jasa memiliki indikator yaitu: Tangibles, Reliabilitas, Responsiveness, Assurance, Emphaty dan Harga memiliki indikator yaitu : Discounting, Odd pricing, Synchropricing serta Kepuasan Konsumen memiliki indikator yaitu : Kesesuaian harapan, Minat berkunjung kembali, Kesediaan merekomendasikan.

\section{METODE PENELITIAN}

Dalam penelitian ini penulis menggunakan metode penelitian survey. Sugiyono (2014:7) mendefinisikan penelitian survey adalah : "Penelitian survey adalah penelitian yang dilakukan pada populasi besar maupun kecil, tetapi data yang dipelajari adalah data dari sampel yang diambil dari populasi tersebut, sehingga ditemukan kejadian-kejadian relative, distribusi, dan hubungan-hubungan antar variabel sosiologis maupun psikologis." Penelitian survey dilakukan untuk membuat generalisasi dari sebuah pengamatan dan hasilnya akan lebih akurat. Metode survey digunakan untuk mendapatkan data dari tempat tertentu yang alamiah (bukan buatan), tetapi peneliti melakukan perlakuan dalam pengumpulan data, misalnya dengan memberikan kuesioner sebagai alat-alat dalam pengambilan data yang pokok, kemudian data yang diperoleh dibahas secara sistematis sehingga diperoleh kesimpulan.

\section{Sampel}

Populasi adalah wilayah generalisasi yang terdiri atas obyek atau subyek yang mempunyai kualitas dan karakteristik tertentu yang ditetapkan oleh peneliti untuk dipelajari dan kemudian ditarik kesimpulannya (Sugiyono. 2014:119). Populasi juga merupakan seluruh karakteristik yang menjadi objek penelitian, dimana karakteristik tersebut berkaitan dengan seluruh kelompok orang, peristiwa, atau benda yang menjadi pusat perhatian bagi peneliti. Dengan kata lain populasi adalah himpunan keseluruhan objek yang diteliti (Thoifah.2015:19). Sedangkan 
sampel adalah bagian dari jumlah dan karakteristik yang dimiliki oleh populasi tersebut sampel yang diambil dari populasi tersebut harus betul-betul representative (mewakili). Ukuran sampel merupakan banyaknya sampel yang akan diambil dari suatu populasi Sugiyono (2012:73).

Menurut Arikunto (2012:104) jika jumlah populasinya kurang dari 100 orang, maka jumlah sampelnya diambil secara keseluruhan, tetapi jika populasinya lebih besar dari 100 orang, maka bisa diambil 10-15\% atau 20-25\% dari jumlah populasinya. Berdasarkan penelitian ini karena jumlah populasinya tidak lebih besar dari 100 orang responden, maka penulis mengambil 100\% jumlah populasi di penelitian ini yaitu sebanyak 60 orang responden dengan rata-rata 2 responden dalam satu hari maka peneliti akan meneliti selama 30 hari. Adapun metode penggambilan sampel menggunakan metode sensus dimana seluruh populasi dijadikan sampel jadi sampel di penelitian ini berjumlah 60 0rang.

\section{Metode pengumpulan data}

Metode pengumpulan data yang digunakan dalam penelitian ini adalah dengan metode kuesioner. Kuesioner merupakan suatu teknik pengumpulan dengan memberikan atau menyebarkan daftar pertanyaan kepada responden dengan harapan memberikan respons atas daftar pertanyaan tersebut. Daftar pertanyaan dapat bersifat terbuka, yaitu jika jawaban tidak ditentukan sebelumnya oleh peneliti dan dapat bersifat tertutup, yaitu akternatif jawaban telah ditentukan sebelumnya oleh peneliti. Adapun instrumen daftar pertanyaan dapat berupa pertanyaan (berupa isian yang akan diisi oleh responden), checklist (berupa pilihan dengan cara memberi tanda pada kolom yang disediakan), dan skala (berupa pilihan dengan memberi tanda pada kolom berdasarkan tingkatan tertentu). (Noor. $2015: 138)$.

Terdapat empat komponen inti dari sebuah kuesioner, yaitu : (1) adanya subyek, yaitu individu atau lembaga yang melaksanakan penilitian; (2) adanya ajakan, yaitu permohonan dari peneliti kepada responden untuk turut serta mengisi atau menjawab pertanyaan secara aktif dan objektif; (3) adanya petunjuk pengisian kuesioner, yaitu petunjuk yang tersedia harus mudah dimengerti dan tidak bias(mempunyai persepsi yang macam macam); dan (4) adanya pertanyaan atau pernyataan berserta tempat untuk mengisi jawaban, baik secara tertutup maupun terbuka. Dalam kuesioner harus ada identitas responden (nama responden dapat tidak dicantumkan). (Noor,2015:139)

Tabel 1. Skala likert

\begin{tabular}{|l|l|}
\hline Pilihan Jawaban & Skor Jawaban \\
\hline Sangat Setuju (SS) & 5 \\
\hline Setuju (S) & 4 \\
\hline Cukup Setuju (CS) & 3 \\
\hline Tidak Setuju (TS) & 2 \\
\hline Sangat Tidak Setuju (STS) & 1 \\
\hline
\end{tabular}

Sumber : (Sugiyono,2009:133) 


\section{Metode Analisis}

Metode yang digunakan dalam penelitian ini adalah sebagai berikut :

a. Korelasi Spearman Rank

Menurut Sugiyono (2015:244) Korelasi Spearman Rank adalah korelasi digunakan untuk mencari hubungan atau menguji signifikansi hipotesis asosiatif bila masing masing variabel yang dihubungkan berbentuk ordinal, dan sumber data antara variabel tidak harus sama. Adapun rumus dari korelasi Spearman Rank yaitu sebagai berikut:

Untuk mengetahui ada atau tidaknya hubungan atau korelasi antara variabel yang diteliti digunakan interpretasi korelasi sebagai berikut :

Tabel 2. Interpretasi Korelasi

\begin{tabular}{|l|l|}
\hline Interval Koefisien & Tingkat Hubungan \\
\hline $0,00-0,199$ & Sangat rendah \\
\hline $0,20-0,399$ & Rendah \\
\hline $0,40-0,599$ & Sedang \\
\hline $0,60-0,799$ & Kuat \\
\hline $0,80-0,1000$ & Sangat kuat \\
\hline
\end{tabular}

Sumber : Sugiyono (2015:231)

a. Uji hipotesis

Untuk mengetahui apakah uji hipotesis yang diajukan dalam penelitian ini diterima atau ditolak digunakan uji hipotesis. Uji hipotesis dalam penelitian uni menggunakan uji $\mathrm{T}$, dikarenakan sampel dalam penelitian ini $>30$ responden. Adapun Rumus yang digunakan menurut Sugiyono (2014:250) dalam menguji hipotesis (Uji t) penelitian ini adalah:

$$
\mathrm{t}=\mathrm{r} \frac{\sqrt{\mathrm{n}-2}}{\sqrt{1-\mathrm{r}^{2}}}
$$

Kriteria pengujian hipotesis dengan uji $\mathrm{T}$ adalah

1. Tingkat keyakinan $95 \%$ atau $\alpha=0,05$

2. Jika $\mathrm{T}$ hitung $>\mathrm{T}$ tabel, Ho ditolak dan Ha diterima, yang berarti bahwa terdapat hubungan positif dan signifikan antara kualitas jasa dan harga dengan kepuasan konsumen Panasonic Service Center Bengkulu.

3. Jika $\mathrm{T}$ hitung $<\mathrm{T}$ tabel, Ho diterima dan Ha ditolak, yang berarti bahwa tidak terdapat hubungan positif dan signifikan antara kualitas jasa dan harga dengan kepuasan konsumen Panasonic Service Center Bengkulu.

Untuk memudahkan dalam penganalisisan data, digunakan bantuan aplikasi SPSS versi 17 for windows.

\section{HASIL PENELITIAN DAN PEMBAHASAN}

\section{Hasil Uji Validitas}

Uji validitas digunakan untuk menguji tingkat kevalidan butir pertanyaan masingmasing variabel. Butir pertanyaan dikatakan valid jika mampu mengukur apa yang 
diinginkan dan dapat mengungkapkan data dari variabel yang diteliti secara tepat. Jika perhitungan $r$ sama dengan atau lebih besar dari $r$ tabel maka butir- butir pertanyaan tersebut dikatakan valid. Sebaliknya jika perhitungan $r$ lebih kecil daripada $\mathrm{r}$ tabel maka butir-butir pertanyaan dikatakan tidak valid. Hasil uji validitas dikonsultasikan pada $r$ tabel pada taraf signifikansi 5\% dengan $n=60$ sampel adalah sebesar 0,254. Hasil uji validitas pada variabel kualitas jasa dapat dilihat pada tabel 6 berikut ini :

Tabel 6

Hasil Uji validitas variabel kualitas jasa

\begin{tabular}{|l|l|l|l|l|}
\hline No Item & r hitung & r tabel 5\% (60) & Sig. & Kriteria \\
\hline 1 & 0,706 & 0,254 & 0,000 & Valid \\
\hline 2 & 0,760 & 0,254 & 0,000 & Valid \\
\hline 3 & 0,828 & 0,254 & 0,000 & Valid \\
\hline 4 & 0,718 & 0,254 & 0,000 & Valid \\
\hline 5 & 0,695 & 0,254 & 0,000 & Valid \\
\hline 6 & 0,646 & 0,254 & 0,000 & Valid \\
\hline 7 & 0,671 & 0,254 & 0,000 & Valid \\
\hline 8 & 0,542 & 0,254 & 0,000 & Valid \\
\hline No Item & r hitung & r tabel 5\% (60) & Sig. & Kriteria \\
\hline 9 & 0,685 & 0,254 & 0,000 & Valid \\
\hline 10 & 0,603 & 0,254 & 0,000 & Valid \\
\hline Sumber : Da & dion 2019 & & \\
\hline
\end{tabular}

Sumber : Data diolah, 2019

Tabel 7

Hasil Uji validitas variabel harga

\begin{tabular}{|l|l|l|l|l|}
\hline No Item & r hitung & r tabel 5\% (60) & Sig. & Kriteria \\
\hline 1 & 0,739 & 0,254 & 0,000 & Valid \\
\hline 2 & 0,686 & 0,254 & 0,000 & Valid \\
\hline 3 & 0,737 & 0,254 & 0,000 & Valid \\
\hline 4 & 0,580 & 0,254 & 0,000 & Valid \\
\hline 5 & 0,616 & 0,254 & 0,000 & Valid \\
\hline 6 & 0,601 & 0,254 & 0,000 & Valid \\
\hline 7 & 0,642 & 0,254 & 0,000 & Valid \\
\hline 8 & 0,611 & 0,254 & 0,000 & Valid \\
\hline 9 & 0,390 & 0,254 & 0,002 & Valid \\
\hline 10 & 0,555 & 0,254 & 0,000 & Valid \\
\hline
\end{tabular}

Sumber : Data diolah, 2019 
Tabel 8

Hasil Uji validitas variabel kepuasan konsumen

\begin{tabular}{|l|ll|ll|}
\hline No Item & $\mathbf{r}$ hitung & r tabel 5\% (60) & Sig. & Kriteria \\
\hline 1 & 0,803 & 0,254 & 0,000 & Valid \\
\hline 2 & 0,816 & 0,254 & 0,000 & Valid \\
\hline 3 & 0,759 & 0,254 & 0,000 & Valid \\
\hline 4 & 0,740 & 0,254 & 0,000 & Valid \\
\hline 5 & 0,648 & 0,254 & 0,000 & Valid \\
\hline 6 & 0,699 & 0,254 & 0,000 & Valid \\
\hline 7 & 0,600 & 0,254 & 0,000 & Valid \\
\hline 8 & 0,711 & 0,254 & 0,000 & Valid \\
\hline 9 & 0,735 & 0,254 & 0,000 & Valid \\
\hline 10 & 0,743 & 0,254 & 0,000 & Valid \\
\hline
\end{tabular}

Sumber : Data diolah, 2019

Berdasarkan hasil uji validitas pada variabel kepuasan konsumen, diketahui dari 10 butir pertanyaan diperoleh nilai $\mathrm{r}$ hitung > r tabel, sehingga 10 butir pertanyaan pada variabel kepuasan konsumen dinyatakan valid.

Hasil Uji Reliabilitas

Tabel 9

Hasil Uji Reliabilitas

\begin{tabular}{|c|c|c|}
\hline Variabel & $\begin{array}{l}\text { Koefisien Alpha } \\
\text { Cronbach }\end{array}$ & Keterangan \\
\hline Kualitas jasa (X1) & \multicolumn{2}{|c|}{ 0,874Reliabel } \\
\hline Harga (X2) & \multicolumn{2}{|c|}{ 0,811Reliabel } \\
\hline Kepuasan Konsumen (Y) & \multicolumn{2}{|c|}{ 0,900Reliabel } \\
\hline
\end{tabular}

Sumber : Data diolah, 2019

Berdasarkan hasil uji reliabilitas diketahui, seluruh variabel penelitian mempunyai nilai koefisien Alpha Cronbach lebih besar dari 0,600 sehingga instrument penelitian dinyatakan reliabel dan layak digunakan untuk pengambilan data penelitian.

\section{Hasil Analisis Korelasi Rank Spearman}

Analisis korelasi Rank Spearman digunakan untuk mengetahui hubungan kualitas jasa dan harga dengan kepuasaan konsumen pada Panasonic Service Center Bengkulu sesuai dengan tujuan penelitian. Berdasarkan hasil penelitian dan analisis data, diperoleh hasil berikut ini.

1. Hubungan kualitas jasa dengan kepuasaan konsumen

Untuk mengetahui bagaimana hubungan kualitas jasa dengan kepuasan konsumen di Panasonic Service Center Bengkulu, dianalisis dengan menggunakan korelasi Rank Spearman. Hasil analisisnya sebagaimana terlihat pada Tabel 10 berikut ini 
Tabel 10

Hasil Output SPSS Kualitas Jasa dengan Kepuasaan Konsumen

\begin{tabular}{|ll|r|r|}
\hline & & X1 & \multicolumn{1}{|c|}{ Y } \\
\hline $\begin{array}{l}\text { Spearman's } \\
\text { rho }\end{array}$ & KUALITAS Correlation Coefficient & 1.000 & 0.790 \\
& JASA (X1) $\quad$ Sig. (2-tailed) & & 0.000 \\
& $\mathrm{~N}$ & 60 & 60 \\
\cline { 2 - 4 } & KEPUASAN Correlation Coefficient Sig. & 0.790 & 1.000 \\
& KONSUMEN (2-tailed) & 0.000 & \\
& $(\mathrm{Y})$ & $\mathrm{N}$ & 60 \\
\hline
\end{tabular}

**. Correlation is significant at the 0.01 level (2-tailed).

Sumber : Data diolah, 2019

Keterangan :

$0,000-0,199=$ Sangat Lemah

$0,200-0,399=$ Lemah

$0,400-0,599=$ Cukup Kuat

$0,600-0,799=$ Kuat

$0,800-1,000=$ Sangat Kuat

Berdasarkan hasil perhitungan korelasi Rank Spearman diperoleh koefisien korelasi antara kualitas jasa dengan kepuasaan konsumen sebesar 0,790. Hasil ini berarti bahwa terdapat hubungan yang kuat antara kualitas jasa dengan kepuasaan konsumen karena berada pada interval 0,600 - 0,799. Dapat disimpulkan bahwa hubungan kualitas jasa dengan kepuasaan konsumen adalah positif. Artinya, apabila kualitas jasa baik, maka kepuasaan konsumen akan meningkat.

2. Hubungan Harga dengan Kepuasaan Konsumen

Hasil analisis hubungan harga dengan kepuasan konsumen dianalisis dengan korelasi Rank Spearman. Hasil analisisnya sebagaimana terlihat pada Tabel 11.Berdasarkan hasil perhitungan korelasi Rank Spearman sebagaimana terangkum pada tabel 11, diperoleh koefisien korelasi antara harga dengan kepuasan konsumen sebesar 0,630. Hasil ini berarti bahwa terdapat hubungan yang kuat antara harga dengan kepuasan konsumen karena berada pada interval $0,600-0,799$.

Tabel 11

Hasil Output SPSS Harga dengan Kepuasaan Konsumen

\begin{tabular}{|c|c|c|c|}
\hline & & $\mathrm{X} 2$ & $\bar{Y}$ \\
\hline \multirow[t]{2}{*}{$\begin{array}{l}\text { Spearman's } \\
\text { rho }\end{array}$} & $\begin{array}{c}\text { HARGA(X2)Correlation Coefficient } \\
\text { Sig. (2-tailed) } \\
\text { N }\end{array}$ & $\begin{array}{r}1.000 \\
60\end{array}$ & $\begin{array}{r}0.630 \\
0.000 \\
60\end{array}$ \\
\hline & $\begin{array}{l}\text { KEPUASAN Correlation Coefficient } \\
\text { KONSUMEN Sig. (2-tailed) (Y) } \\
\text { N }\end{array}$ & $\begin{array}{r}0.630^{* *} \\
0.000 \\
60\end{array}$ & $\begin{array}{r}1.000 \\
60\end{array}$ \\
\hline
\end{tabular}


Keterangan :

$0,000-0,199$

$=$ Sangat Lemah

$0,200-0,399$

$=$ Lemah

$0,400-0,599$

$=$ Cukup Kuat

$0,600-0,799$

$=$ Kuat

$0,800-1,000$

$=$ Sangat Kuat

Nilai koefisien korelasi antara harga dengan kepuasan konsumen tersebut menunjukkan angka positif, dan disimpulkan bahwa hubungan harga dengan kepuasan konsumen adalah positif. Artinya, apabila harga terjangkau maka kepuasan konsumen akan meningkat.

\section{Hasil Pengujian Hipotesis}

Hasil pengujian hipotesis terhadap koefisien korelasi variable kualitas jasa dan harga dengan kepuasan konsumen di Panasonic Service Center Bengkulu. Hasil pengujian hipotesis adalah sebagai berikut :

\section{Hubungan Variabel Kualitas Jasa dengan Kepuasan Konsumen}

Dari rumus diperoleh nilai t-hitung sebesar 9,816> t-tabel 1,672. Hasil ini menunjukkan bahwa terdapat hubungan yang signifikan antara kualitas jasa dengan kepuasan konsumen di Panasonic Service Center Bengkulu.

\section{Hubungan Variabel Harga dengan Kepuasan Konsumen}

Untuk menguji signifikan atau tidaknya hubungan vaiabel harga dengan kepuasan konsumen, maka dihitung dengn rumus sebagai berikut :

Dari rumus diatas diperoleh nilai t-hitung sebesar 6,178 > t-tabel 1,672. Hasil ini menunjukkan bahwa terdapat hubungan yang signifikan antara harga dengan kepuasan konsumen di Panasonic Service Center Bengkulu.

\section{PEMBAHASAN}

Dari hasil penelitian yang telah diperoleh, dapat diketahui bahwa kualitas jasa dan harga memiliki hubungan yang signifikan dengan kepuasan konsumen di Panasonic Service Center Bengkulu. Pada pemaparan berikut ini akan dijelaskan hubungan tersebut sebagai berikut :

1. Hubungan Kualitas Jasa dengan Kepuasan Konsumen

Dari hasil pengujian hipotesis diketahui bahwa variabel kualitas jasa berhubungan kuat dengan kepuasan konsumen, karena berada pada skala 0,600 - 0,799 yang masuk dalam kategori kuat. Hasil dari pengujian hipotesis hubungan yang terjadi antara variabel kualitas jasa dengan kepuasan konsumen adalah positif signifikan, yang dibuktikan dengan nilai t-hitung masing-masing variabel sebesar 9,816 lebih besar dari pada nilai t-tabel 1,672. Hasil ini bermakna bahwa jika kualitas jasa baik, maka kepuasaan konsumen akan meningkat. 
Hasil penelitian ini sesuai dengan teori yang dikemukakan oleh Zeithaml, Bitner dan Gremler (2009:111) mengenai dimensi kualitas jasa yang mempengaruhi kepuasan konsumen yaitu adalah bukti fisik ( tangibles), keandalan (reliability), daya tanggap (responsiveness), jaminan (assurance), empati (emphaty). Hal ini sesuai dengan penelitian Wildan Sulaksana (2016), dimana variabel kualitas jasa meliputi dimensi bukti fisik (tangibles), keandalan (reliability), daya tanggap (responsiveness), jaminan (assurance), empati (emphaty) memiliki pengaruh yang signifikan terhadap variabel kepuasan konsumen.

2. Hubungan Harga dengan Kepuasan Konsumen

Berdasarkan hasil pengujian hipotesis diketahui bahwa variabel harga berhubungan kuat dengan kepuasan konsumen, karena berada pada skala 0,600 - 0,799 yang masuk dalam kategori kuat. Hasil dari pengujian hipotesis hubungan yang terjadi antara variabel harga dengan kepuasan konsumen adalah positif signifikan, yang dibuktikan dengan nilai t-hitung masing-masing variabel sebesar 6,178 lebih besar dari pada nilai t-tabel 1,672. Hasil ini bermakna bahwa jika harga terjangkau maka kepuasan konsumen akan meningkat. Hasil penelitian ini sesuai dengan teori yang dikemukakan oleh Malik et, al (2012:123) kepuasan konsumen juga langsung dipengaruhi oleh faktor harga. Harga mempengaruhi kepuasan konsumen dengan cara positif. Konsumen akan merasa puas jika harga sesuai dengan kualitas yang diharapkan oleh konsumen. Dimensi harga yang mempengaruhi kepuasan konsumen yaitu adalah potongan harga (discounting), harga ganjil (odd pricing), harga sinkronisasi (syncho-pricing). Hal ini sesuai dengan penelitian Ari Setyo (2012) dimana variabel harga meliputi dimensi potongan harga (discounting), harga ganjil (odd pricing), harga sinkronisasi (syncho- pricing) memiliki pengaruh yang signifikan terhadap variabel kepuasan konsumen.

\section{KESIMPULAN DAN SARAN}

\section{Kesimpulan}

1. Variabel kualitas jasa berhubungan signifikan dengan kepuasan konsumen di Panasonic Service Center Bengkulu, dengan nilai koefisien korelasi sebesar 0,790 dan nilai t-hitung 9,816 > t-tabel 1,672. Hasil ini bermakna bahwa jika kualitas jasa baik, maka kepuasaan konsumen akan meningkat.

2. Variabel harga berhubungan signifikan dengan kepuasan konsumen di Panasonic Service Center Bengkulu, dengan nilai koefisien korelasi sebesar 0,630 dan nilai t-hitung 6,178>t-tabel 1,672. Hasil ini bermakna bahwa jika harga terjangkau maka kepuasan konsumen akan meningkat.

\section{Saran}

Berdasarkan hasil penelitian dan pembahasan beberapa saran yang dapat disumbangkan bagi Panasonic Service Center Bengkulu adalah :

1. Untuk kualitas jasa agar dapat memenuhi kepuasan konsumen menurut hasil kuesioner hendaknya harus meningkatkan kehandalan (realibility) terutama karyawan dapat memberikan layanan jasa tepat waktu. 
2. Untuk harga agar dapat memenuhi kepuasan konsumen menurut hasil kuesioner bahwa harga jasa servis produk baru hendaknya tidak dikenakan biaya.

\section{DAFTAR PUSTAKA}

Alma, Buchari. 2013. Manajemen Pemasaran Dan Pemasaran Jasa. Bandung : Alfabeta.

Arikunto, Suharsimi. 2012. Prosedur Penelitian Suatu Pendekatan Praktek. Jakarta: Rineka Cipta.

Dharmmesta, Basu Swastha., Handoko, T. Hani. 2012. Manajemen Pemasaran Analisis Perilaku Konsumen. Edisi Pertama. Yogyakarta. BPFE

Ianatut, Thoifah. 2015. Statistika Pendidikan Dan Metode Penelitian Kuantitatif. Malang : madani.

Kotler, Philip dan Kevin Lane Keller. 2009. Alih Bahasa : Benyamin Molan. Manajemen Pemasaran. Edisi Ketiga belas. Jilid 1. Cetakan Keempat. Jakarta : PT. Indeks.

- 2010. Manajemen Pemasaran. Edisi tiga belas Bahasa Indonesia.Jilid 1 dan 2. Jakarta : Penerbit Erlangga.

, Amstrong Gary. 2012. Prinsip-Prinsip Pemasaran, Edisi 13

Jilid 1.Jakarta : Penerbit Erlangga

Lovelock, C, dan John Wirtz, 2011. Pemasaran Jasa Perspektif, edisi 7. Jakarta :Penerbit Erlangga.

Machfoedz, Mahmud. 2010, Komunikasi Pemasaran Modern, Cetakan Pertama, Yogyakarta: Penerbit Cakra Ilmu

Morissan,M.A. 2010. Media Penyiaran. Jakarta : ramdina prakassa. Nirwana. 2012. Prinsip- Prinsip Pemasaran Jasa. Malang : penerbit dioma

Purnama, Rochmact Aldy. 2016. Analisis Statistik Ekonomi Dan Bisnis Dengan SPSS. Ponorogo : CV. Wade Group

Sugiyono.2009. Metode Penelitian Bisnis. Bandung : Alfabeta

Sugiyono. 2014. Metode Penelitian Pendidikan Pendekatan Kuantitatif,Kualitatif dan $R \& D$. Bandung : Alfabeta 2015. Statistika Untuk Penelitian. Bandung : Alfabeta. 
JURNAL ILMIAH AKUNTANSI, MANAJEMEN \& EKONOMI ISLAM (JAM-EKIS)

VOLUME 3, NO.2, JULI 2020

Tjiptono, Fandy. 2011. Pemasaran Jasa. Yogyakarta: Bayumedia Publishing.

Widiyono dan mukhaer pakkana.2013. Pengantar Bisnis : Respon Terhadap DinamikaGlobal.Jakarta:MitraWacanaMedia 